\title{
Assessment of Renal Functions in Infants and Children with Congenital Heart Diseases
}

\author{
Mohamed Seif Mohamed*, Moftah Mohammed Rabeea *, Hassan Saad Abu Saif * and Kamel \\ Soliman Hammad**
}

*Pediatric Department, **Clinical Pathology Department, Faculty of Medicine, Al-Azhar University

Corresponding author: Doctor Mohammad Seif Taha, email:dr.seifpediatrics@gmail.com

\begin{abstract}
Background: children with congenital heart diseases have a number of risk factors for potential development of chronic kidney diseases later in life such as : including pathophysiological changes related to a structurally abnormal heart, polycythemia, cyanosis and chronic hypoxia change in renal blood flow and intraglomerular hemodynamics with derangements in neurohormonal activation. Objectives: this study aimed to assess renal functions in infants and children with congenital heart diseases and to compare renal functions between children with congenital cyanotic and acyanotic heart diseases.

Patients and Methods: this across sectional case control study was carried out on 50 infants and children with congenital heart diseases (25 patients with congenital acyanotic heart diseases (Group A) and 25 with congenital cyanotic heart diseases (Group B) who were attended at the Pediatric Cardiology Units at Al-Azhar University Hospitals (El-Hussein and Bab El-Sheryia Hospitals) and apparently 25 healthy children age and sex matched included as a control group (Group C). Their age ranged from one month to 5 years old. Patients were subjected to full history taking, full medical examination which included the heart and abdomen and laboratory investigations which included complete blood picture, urine analysis, estimation of glomerular filtration rate, urinary albumin creatinine ratio. Data were collected, tabulated and statistically analyzed. Results: comparing both groups $\mathrm{A}$ and $\mathrm{B}$ by group $\mathrm{C}$ as regards renal functions results; group $\mathrm{B}$ had higher values in all parameters (Estimated glomerular filtration rate (EGFR) and urinary albumin and creatinine ratio.

Conclusion: risk of renal dysfunctions increase by time especially in children with cyanotic CHD which may be due to effect of chronic hypoxia and other conditions such as polycythemia.

Key words: congenital heart diseases, with congenital acyanotic heart diseases, congenital cyanotic heart diseases, glomerular filtration rate (eGFR), urinary albumin creatinine ratio.
\end{abstract}

\section{Introduction:}

Children with congenital heart disease have a number of risk factors for potential development of chronic kidney later in life, including pathophysiological changes related to a structurally abnormal heart and circulation. These include polycythemia, cyanosis and chronic hypoxia changes in renal blood flow and intraglomerular hemodynamics, and derangements in neurohormonal activation ${ }^{(\mathbf{1})}$.

Several studies have revealed that nephropathy is a prominent feature and a potential complication of congenital cyanotic heart diseases ${ }^{(2)}$.

It has been documented that chronic cyanosis affects renal glomerular structure and function in the kidney. The structural hallmark of glomerular injury in patients with congenital cyanotic heart disease had been described as glomerulomegaly, capillary dilatation, thickening of the capillary walls, focal or diffused proliferation of mesangial cells and segmental or global glomerulosclerosis. Although proteinuria is the major urinary abnormality in patients with cyanotic congenital heart disease, nephrotic syndrome is an uncommon complication and renal biopsy has been seldom performed. Adverse effects of chronic hypoxia on renal tubular function have been less frequently documented. Secondary renal tubular acidosis seemed to be an acquired complication in patients with chronic cyanosis ${ }^{(3)}$.

\section{Aim of the work:}

This study aimed to assess renal functions in infants and children with congenital heart diseases and to compare renal functions between children with congenital cyanotic and acyanotic heart diseases.

\section{Patients and Methods:}

This was a cross sectional study and it was carried out on fifty infants and children with CHD from those attending the Pediatric Cardiology Units at Al-Azhar University Hospitals (El-Hussein and Bab El-Sheryia Hospitals). They were enrolled in this case control study to evaluate renal functions in both cyanotic and acyanotic congenital heart diseases. 
They were categorized into two groups as following:

Group A: 25 acyanotic CHD patients.

Group B: $\quad 25$ cyanotic CHD patients.

Also twenty five apparently healthy children age and sex matched with patients who came for health were included as a control group (Group C).

Each group was divided into subgroups according to the age as follow:

- $\quad$ From the age of one month to one year and they were named subgroups A1, B1, C1.

- $\quad$ After the age of one year and up to the age of five years they were named subgroups A2,

\section{B2, C2.}

Written consent was taken from parents of each child. All risks and benefits of the study were explained to all parents of patients and they have the right to withdraw from this work without giving any reasons.

\section{Ethical considerations:}

1. Written consent for the study was obtained from the parents or caregivers.

2. Approval of the local committee in the pediatrics department, college and university were obtained before the study.

3. There is no conflict of interest regarding the study, authorship and publication.

4. The data of the patients and the results of the study are confidential and the patients have the right to keep.

5. The authors received no financial support for the study or the publication.

6. The patients had the right to withdraw from the study at any time.

\section{Inclusion criteria:}

All infants and children with congenital heart diseases age ranged from 1month-5 years old.

\section{Exclusion criteria: \\ 1-Neonates \\ 2-Patients with congenital anomalies \\ 3-Patients with renal or urinary tract anomlies \\ 4-Patients with acute or chronic urinary tract infections \\ 5-Patients with endocarditis, diabetes mellitus and acute infections \\ 6-Recently used nephrotoxic drugs}

\section{Methods:}

All infants and children participating in this study were subjected to the following:
Detailed history with stress history of onset and duration of cyanosis, symptoms of cyanotic spells, squatting, urinary manifestations as (polyurea, oligurea, change in colour of urine, etc).Complete general examination included: vital data (Blood pressure in 4 limbs, pulse, saturation, etc) clubbing, peripheral pulsations and all body systems.Local examination of the heart : apex, pericardial pulge, vessible pulsations, cardiac auscultation(1st and 2 nd heart sounds and murmurs).

Routine investigations: CBC, CRP, ESR, ABG. Complete urine analysis especially for proteinurea, hematurea, pyurea.

Renal function tests (Seum creatinine and serum urea).

Serum electrolytes (Na, K) serum uric acid.

Protein / creatinine ratio in urine in selected cases if indicated.

Pelviabdominal ultrasound.

Echocardiography (M mode, two dimentional Doppler colour and pulsed echocardiography).

\section{Statistical analysis:}

Comparison between numerical data was performed using unpaired $t$ test while, comparison between before and after bran intake within the same group was performed using paired $t$ test. Comparison between categorical data was performed using Chi square test. SPSS computer program (version 20) was used for data analysis. Data were statistically described in terms of mean \pm standard deviation $( \pm \mathrm{SD})$ or number (\%). Difference in variables was expressed by $\mathrm{P}$ value (. 0.05 is significant and > 0.05 is non-significant).

\section{Results:}

\section{Demographic data}

This study was carried out on 50 children who were diagnosed to have congenital heart disease; 25 of them with acyanotic lesions (group A) while, the remaining 25 children were with cyanotic lesions (group B) from those attending Pediatric Cardiology Units at Al-Azhar University Hospitals (El-hussein and Sayed Galal Hospitals). Also, anther 25 normal children were taken as the control group (Group C). Each group was divided into 2 subgroups according to their age:

From the age of one month to one year and are named subgroups A1, B1, C1.

The age of one year and up to the age of five years was named subgroups A2, B2, C2. 
Table (2): comparison between the studied groups A1, B1 and C1 according to demographic data

\begin{tabular}{|c|c|c|c|c|c|c|c|c|}
\hline & \multicolumn{2}{|c|}{ A1 } & \multicolumn{2}{|c|}{ B1 } & \multicolumn{2}{|c|}{ C1 } & \multirow{2}{*}{ Test of sig. } & \multirow{2}{*}{$\mathbf{P}$} \\
\hline & No. & $\%$ & No. & $\%$ & No. & $\%$ & & \\
\hline \multicolumn{9}{|l|}{ Sex } \\
\hline Male & 7 & 53.8 & 8 & 61.5 & 7 & 53.8 & \multirow{2}{*}{$\chi^{2}=0.209$} & \multirow{2}{*}{0.901} \\
\hline Female & 6 & 46.2 & 5 & 38.5 & 6 & 46.2 & & \\
\hline \multicolumn{9}{|l|}{ Age months } \\
\hline Min. - Max. & \multicolumn{2}{|c|}{$2.0-12.0$} & \multicolumn{2}{|c|}{$2.0-9.0$} & \multicolumn{2}{|c|}{$1.0-9.0$} & & \\
\hline Mean \pm SD & \multicolumn{2}{|c|}{$4.19 \pm 2.56$} & \multicolumn{2}{|c|}{$4.04 \pm 2.38$} & \multicolumn{2}{|c|}{$4.81 \pm 2.48$} & ${ }^{\mathrm{KW}} \chi^{2}=1.305$ & 0.521 \\
\hline Median & \multicolumn{2}{|c|}{3.50} & \multicolumn{2}{|c|}{3.0} & \multicolumn{2}{|c|}{5.0} & & \\
\hline
\end{tabular}

$\chi 2$ : Chi square test

$\mathrm{KW} \chi 2$ : Chi square for Kruskal Wallis test

*: Statistically significant at $\mathrm{p} \leq 0.05$

Table 3: comparison between the studied groups A2, B2 and C2 according to demographic data

\begin{tabular}{|c|c|c|c|c|c|c|c|c|}
\hline & \multicolumn{2}{|c|}{ A2 } & \multicolumn{2}{|c|}{ B2 } & \multicolumn{2}{|c|}{$\mathrm{C2}$} & \multirow{2}{*}{ Test of sig. } & \multirow{2}{*}{$\mathbf{P}$} \\
\hline & No. & $\%$ & No. & $\%$ & No. & $\%$ & & \\
\hline $\begin{array}{l}\text { Sex } \\
\quad \text { Male } \\
\text { Female }\end{array}$ & $\begin{array}{l}5 \\
7\end{array}$ & $\begin{array}{l}41.7 \\
58.3\end{array}$ & $\begin{array}{c}11 \\
1\end{array}$ & $\begin{array}{c}91.7 \\
8.3\end{array}$ & $\begin{array}{l}7 \\
5\end{array}$ & $\begin{array}{l}58.3 \\
41.7\end{array}$ & $\chi^{2}=6.840$ & 0.051 \\
\hline $\begin{array}{l}\text { Age months } \\
\text { Min. - Max. } \\
\text { Mean } \pm \text { SD. } \\
\text { Median }\end{array}$ & \multicolumn{2}{|c|}{$\begin{array}{c}13.0-60.0 \\
41.58 \pm 18.62 \\
44.0\end{array}$} & \multicolumn{2}{|c|}{$\begin{array}{c}18.0-47.0 \\
27.42 \pm 11.11 \\
21.50\end{array}$} & \multicolumn{2}{|c|}{$\begin{array}{c}13.0-60.0 \\
35.83 \pm 19.10 \\
36.0\end{array}$} & ${ }^{\mathrm{KW}} \chi^{2}=3.085$ & 0.214 \\
\hline
\end{tabular}

$\chi 2$ : Chi square test

$\mathrm{KW} \chi 2$ : Chi square for Kruskal Wallis test

*: Statistically significant at $\mathrm{p} \leq 0.05$

Table 4: comparison between the studied groups A1, B1 and C1 according to e GFR

\begin{tabular}{|c|c|c|c|c|c|}
\hline & $\overline{A 1}$ & B1 & C1 & Test of sig. & $\overline{\mathbf{P}}$ \\
\hline \multirow{2}{*}{$\begin{array}{l}\text { eGFR } \\
\left(\mathbf{m l} / \mathbf{m i n} / \mathbf{1 . 7 3 m ^ { 2 }}\right) \\
\text { Mean } \pm \text { SD } \\
\text { Median }\end{array}$} & \multirow[b]{2}{*}{$\begin{array}{c}65.36 \pm 11.70 \\
66.38\end{array}$} & \multirow[b]{2}{*}{$\begin{array}{c}55.13 \pm 5.74 \\
59.40\end{array}$} & \multirow[b]{2}{*}{$\begin{array}{c}72.83 \pm 2.85 \\
66.94\end{array}$} & & \\
\hline & & & & & \\
\hline Sig. bet. grps. & \multicolumn{3}{|c|}{$\mathrm{p}_{1}=0.133, \mathrm{p}_{2}=0.268, \mathrm{p}_{3}=0.012^{*}$} & & \\
\hline $\begin{array}{l}\text { Normal } \\
\text { \#Abnormal }\end{array}$ & $\begin{array}{c}13(100.0 \%) \\
0(0.0 \%)\end{array}$ & $\begin{array}{c}11(84.6 \%) \\
2(15.4 \%)\end{array}$ & $\begin{array}{c}13(100.0 \%) \\
0(0.0 \%)\end{array}$ & $\chi^{2}=2.842$ & ${ }^{\mathrm{MC}} \mathrm{p}=0.315$ \\
\hline
\end{tabular}

eGFR = estimated glomerular filteration rate

\#Abnormal value $<29.13\left(\mathrm{ml} / \mathrm{min} / 1.73 \mathrm{~m}^{2}\right)$

$\chi^{2}$ : Chi square test

MC: Monte Carlo test

F: F test (ANOVA), Sig. bet. grps was done using Post Hoc Test (LSD)

$\mathrm{p}_{1}: \mathrm{p}$ value for comparing between $\mathrm{A} 1$ and $\mathrm{B} 1$

$\mathrm{p}_{2}: \mathrm{p}$ value for comparing between $\mathrm{A} 1$ and $\mathrm{C} 1$

$\mathrm{p}_{3}: \mathrm{p}$ value for comparing between $\mathrm{B} 1$ and $\mathrm{C} 1$ 
*: Statistically significant at $\mathrm{p} \leq 0.05$

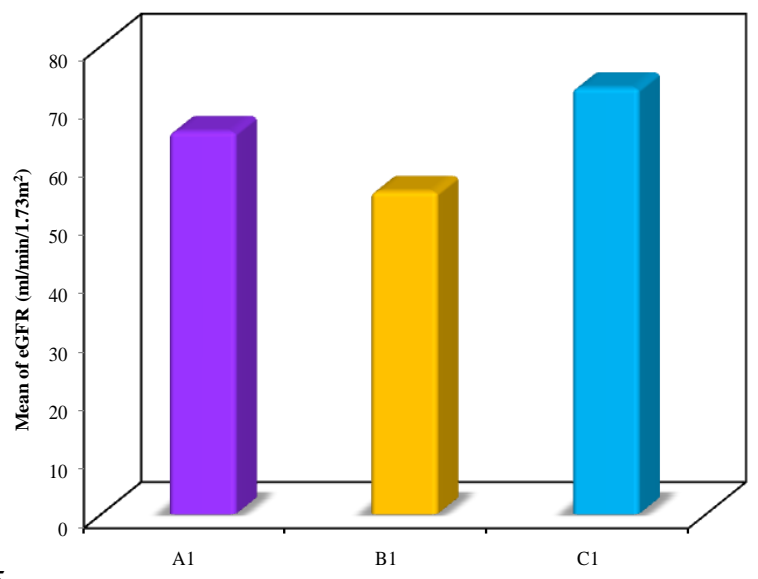

Figure 1: comparison between the studied groups A1, B1 and C1 according to e GFR

Table 5:comparison between the studied groups A2, B2 and C2 according to eGFR

\begin{tabular}{|c|c|c|c|c|c|}
\hline & $\mathbf{A 2}$ & $\mathbf{B 2}$ & $\mathbf{C 2}$ & Test of sig. & $\mathbf{P}$ \\
\hline \multicolumn{6}{|l|}{ eGFR $\left(\mathrm{ml} / \mathrm{min}^{\prime} \mathbf{1 . 7 3 \mathrm { m } ^ { 2 } )}\right.$} \\
\hline Mean \pm SD & $116.62 \pm 21.07$ & $92.86 \pm 17.27$ & $120.92 \pm 19.71$ & & \\
\hline Median & 114.09 & 99.81 & 118.05 & & \\
\hline Sig. bet. grps. & \multicolumn{3}{|c|}{$\mathrm{p}_{1}=0.005^{*}, \mathrm{p}_{2}=0.590, \mathrm{p}_{3}=0.001^{*}$} & & \\
\hline $\begin{array}{l}\text { Normal } \\
{ }^{\#} \text { Abnormal }\end{array}$ & $\begin{array}{c}11(91.7 \%) \\
1(8.3 \%)\end{array}$ & $\begin{array}{l}9(75 \%) \\
3(25 \%)\end{array}$ & $\begin{array}{c}12(100.0 \%) \\
0(0.0 \%)\end{array}$ & $\chi^{2}=3.293$ & ${ }^{\mathrm{MC}} \mathrm{p}=0.289$ \\
\hline
\end{tabular}

eGFR = estimated glomerular filteration rate

\#A bnormal value $<81.5(\mathrm{ml} / \mathrm{min} / 1.73 \mathrm{~m} 2)$

F: F test (ANOVA), Sig. bet. grps was done using Post Hoc Test (LSD)

$\chi 2$ : Chi square test

MC: Monte Carlo test

$\mathrm{p} 1$ : $\mathrm{p}$ value for comparing between $\mathrm{A} 2$ and $\mathrm{B} 2$

$\mathrm{p} 2: \mathrm{p}$ value for comparing between $\mathrm{A} 2$ and $\mathrm{C} 2$

$\mathrm{p} 3$ : $\mathrm{p}$ value for comparing between $\mathrm{B} 2$ and $\mathrm{C} 2$

*: Statistically significant at $\mathrm{p} \leq 0.05$

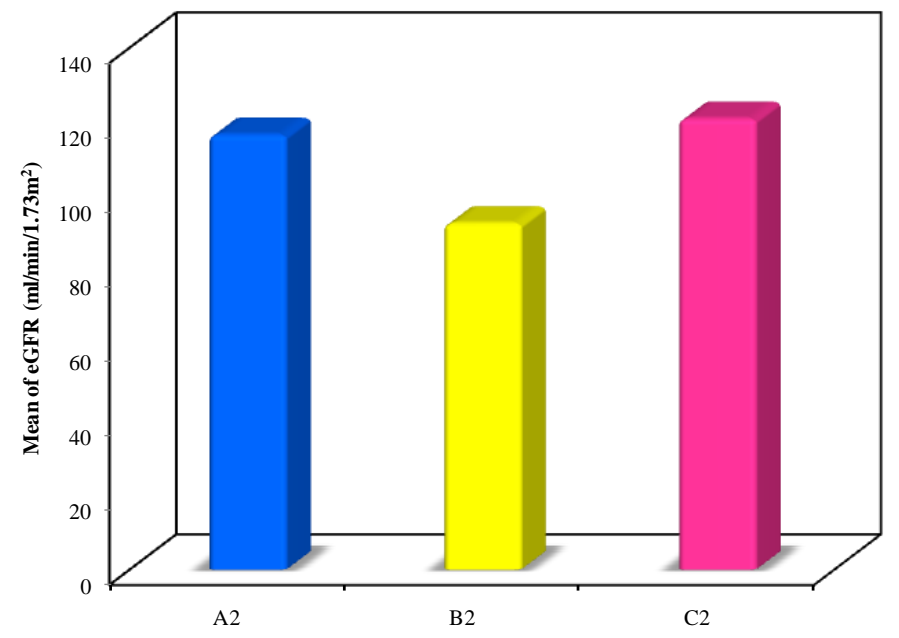

Figure 2: comparison between the studied groups A2, B2 and C2 according to eGFR

Table 6: comparison between the studied groups $\mathrm{A} 1, \mathrm{~B} 1$ and $\mathrm{C} 1$ according to $\mathrm{U} \mathrm{Alb} / \mathrm{Cr}$ ratio

\begin{tabular}{|l|c|c|c|c|c||}
\hline & A1 & B1 & C1 & Test of sig. & P \\
\hline U Alb/Cr ratio & & & & & \\
(mg/g) & & & & & \\
Mean \pm SD. & $38.84 \pm 1.66$ & $46.56 \pm 3.85$ & $36.96 \pm 9.51$ & & \\
Median & 36.27 & 46.0 & 38.0 & & \\
\hline
\end{tabular}




\begin{tabular}{|c|c|c|c|c|c|}
\hline $\begin{array}{l}\text { Normal } \\
{ }^{\#} \text { Abnormal }\end{array}$ & $\begin{array}{c}12(92.3 \%) \\
1(7.7 \%)\end{array}$ & $\begin{array}{c}10(76.9 \%) \\
3(23.1 \%)\end{array}$ & $\begin{array}{c}13(100.0 \%) \\
0(0.0 \%)\end{array}$ & $\chi^{2}=3.257$ & ${ }^{\mathrm{MC}} \mathrm{p}=0.298$ \\
\hline
\end{tabular}

$\mathrm{U} \mathrm{Alb} / \mathrm{Cr}=$ urinary albumin / creatinine ratio $(\mathrm{mg} / \mathrm{g})$

\#Abnormal value $>55.98(\mathrm{mg} / \mathrm{g})$

$\chi 2$ : Chi square test

MC: Monte Carlo test

$\mathrm{KW} \chi 2$ : Chi square for Kruskal Wallis tes

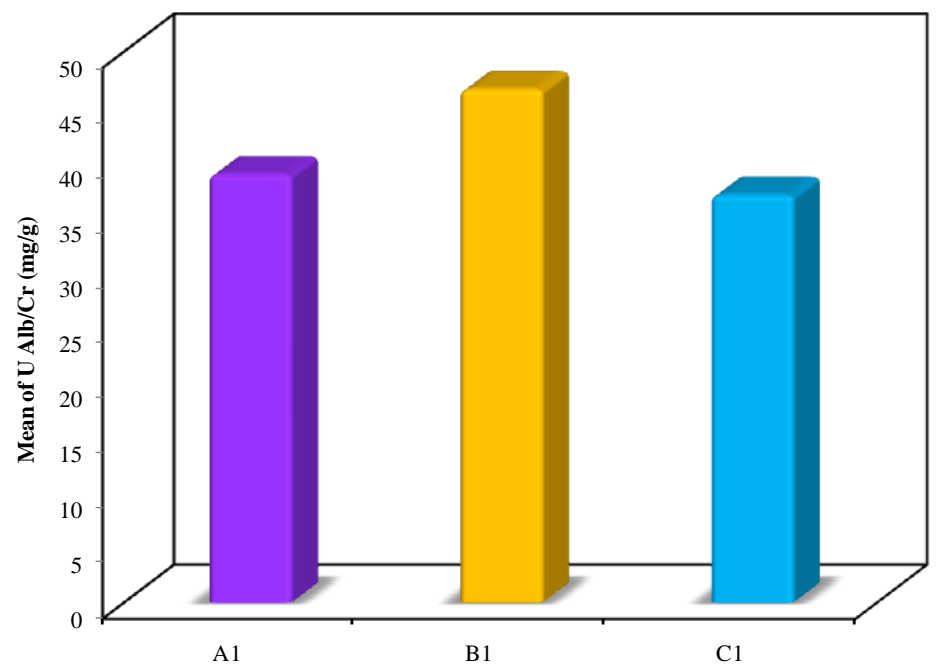

Figure 3: comparison between the studied groups $\mathrm{A} 1, \mathrm{~B} 1$ and $\mathrm{C} 1$ according to $\mathrm{U} \mathrm{Alb} / \mathrm{Cr}$ ratio

Table 7: comparison between the studied groups A2, B2 and $\mathrm{C} 2$ according to $\mathrm{U} \mathrm{Alb} / \mathrm{Cr}$ ratio

\begin{tabular}{|c|c|c|c|c|c|}
\hline & A2 & B2 & C2 & Test of sig. & $\mathbf{P}$ \\
\hline U Alb/Cr (mg/g) & & & & & \\
\hline $\begin{array}{l}\text { Mean } \pm \text { SD. } \\
\text { Median }\end{array}$ & $\begin{array}{c}44.48 \pm 5.07 \\
41.48\end{array}$ & $\begin{array}{c}49.34 \pm 9.69 \\
43.11\end{array}$ & $\begin{array}{c}38.65 \pm 1.84 \\
35.74\end{array}$ & & \\
\hline $\begin{array}{l}\text { Normal } \\
\text { \#Abnormal }\end{array}$ & $\begin{array}{c}10(83.3 \%) \\
2(16.7 \%)\end{array}$ & $\begin{array}{l}8(66.7 \%) \\
4(33.3 \%)\end{array}$ & $\begin{array}{c}11(91.7 \%) \\
1(8.3 \%)\end{array}$ & $\chi^{2}=2.277$ & ${ }^{\mathrm{MC}} \mathrm{p}=0.440$ \\
\hline
\end{tabular}

$\mathrm{U} \mathrm{Alb} / \mathrm{Cr}=$ urinary albumin / creatinine ratio $(\mathrm{mg} / \mathrm{g})$

\#Abnormal value $>60.33(\mathrm{mg} / \mathrm{g})$

$\chi 2$ : Chi square test

MC: Monte Carlo test

$\mathrm{KW} \chi 2$ : Chi square for Kruskal Wallis test

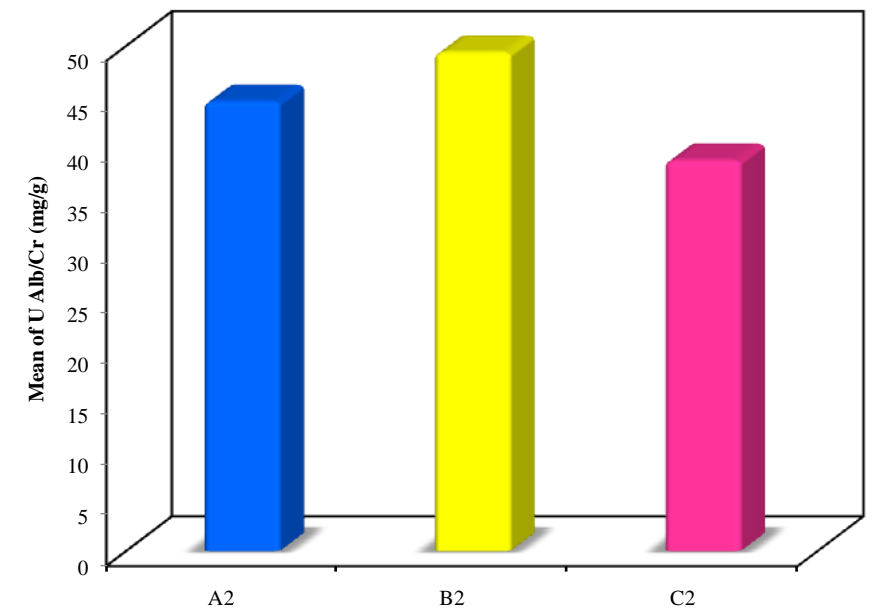

Figure 4: comparison between the studied groups $\mathrm{A} 2, \mathrm{~B} 2$ and $\mathrm{C} 2$ according to $\mathrm{U} \mathrm{Alb} / \mathrm{Cr}$ ratio 


\section{Discussion}

Congenital heart disease is the most common congenital disorder in newborns. They account for about thirty percent of all major birth defects (4).

CHD is one of the leading causes of perinatal and infant death from congenital malformations ${ }^{(5)}$.

There are approximately 1.5 million new cases of CHD per year worldwide. The reported incidence of congenital heart disease at birth ranged from six to thirteen per thousand live births ${ }^{(6)}$.

Etiology of CHD is multifactorial and a large collection of environmental and genetic causes had a role in its pathogenesis ${ }^{(7)}$.

Between $25 \%$ and $30 \%$ of children with CHD had some forms of additional congenital lesion, a comorbidity or structural extracardiac anomaly that may be immediately appeared ${ }^{(8)}$.

However, comorbidity may have an important, even crucial, bearing on the course and outcome of the management of a child with a congenital heart lesion ${ }^{(9)}$.

The renal functions of patients with acyanotic congenital heart disease were less studied and relatively few studies have focused on renal function in infants and young children with congenital heart diseases ${ }^{(\mathbf{1 0})}$.

Serum and urinary biomarkers, both glomerular and tubular, play an important role in the early detection of renal damage. Urine as a diagnostic medium allows for noninvasive detection of biomarkers. Detection of renal tubular proteins and enzymes in the urine demonstrates a tubular involvement that leads to renal complications ${ }^{(11)}$. In the present study, it was found that there was no significant difference between the studied groups regarding sex and age.

(12) studied 20 children with ACHD and 23 children with CCHD and 13 healthy children as control. ${ }^{(10)}$ studied 24 children with ACHD and 20 children with mild CCHD and 14 children with severe CCHD and 20 healthy children as control. ${ }^{(13)}$ studied 34 children with ACHD and 20 children with CCHD and 20 healthy children as control. In the three studies, there were no differences in the demographic characteristics between the three studied groups. In the present study, eGFR was proved that in acyanotic children below age of one year, there were no patients with GFR below normal range while, in cyanotic corresponding age group, there were 2 of 13 patients $(15.4 \%)$ showed abnormal values with significant difference to corresponding control group. In subgroups above one year, there was 1 of 12 acyanotic patients $(8.3 \%)$ showed abnormal value while, 3 of 12 cyanotic patients $(25 \%)$ showed GFR out of normal range with significant difference to both acyanotic and control groups. Although, ${ }^{(12)}$ found that GFR was found to be lower in the cyanotic group, the difference in the mean GFR values among groups was not statistically significant. Also, ${ }^{(10)}$

they found that acyanotic patients group and severe cyanotic patients group did not have a significantly higher eGFR than mild cyanotic patients group. ${ }^{(13)}$ found that there was no any relationship between the presence of cyanosis and GFR level. Though the three studies came as no significant difference between the two acyanotic and cyanotic groups, but they concluded that the eGFR was lowest in CCHD with sever cyanosis. The difference between this data and our study can explained by difference in the age of patients, methods of selection and severity of cyanosis.

Regarding urinary albumin / creatinine ratio in the present study, it was found that in acyanotic children below age of one year, there was 1 of 13 patients $(7.7 \%)$ with $\mathrm{U} \mathrm{Alb} / \mathrm{Cr}$ out of normal range while, in cyanotic corresponding age group, there were 3 patients of $13(23.1 \%)$ showed abnormal values. In subgroups above one year, there were 2 of 12 acyanotic patients (16.7\%) showed abnormal value while, 4 of 12 cyanotic patients $(33.3 \%)$ showed $\mathrm{U}$ Alb/Cr out of normal range. Both acyanotic and cyanotic subgroups with no significant difference to corresponding control subgroups. Similarly, ${ }^{(12)}$ they found that both acyanotic and cyanotic groups had no significant difference to control group or to each other, ${ }^{(10)}$, they proved that there was no significant difference between acyanotic and cyanotic patients groups. But in contrast to our study, $\mathrm{U} \mathrm{Alb/Cr}$ levels in the three patient groups were comparable and significantly higher than that in the control group.

(14) in their study, 72 patients with CCHD were divided into 4 equal groups according to age: G2 (Below 1 year), G3 (Above 1 year and Below 5 years), G4 (above 5 years and Below 10 years) and G5 (above 10 years). In addition to, G1 as control and G6 as cases underwent palliative surgery. In this study, they found that there was a significant difference between the two groups G2 and G3 to each other and to the control group. In our study, absence of significant difference between the studied groups may be due to the fact that microalbuminuria mainly has glomerular origin and in turn, glomerular injury may be 
manifested much later than tubular injury which may be detected even before glomerular injury develops. On other hand, ${ }^{(14)}$ compared between groups differ from each other according to mean of age and then comparing them to single control group which in turn differs from each of them according to mean of age that may lead to apparently significant difference between the studied groups.

\section{Conclusion}

Based on the results of the current study, it can be concluded that children with cyanotic $\mathrm{CHD}$ at higher risk of developing renal dysfunction with its both glomerular and tubular aspects than those with acyanotic CHD. It can also be concluded that risk of renal dysfunctions increased by time especially in children with cyanotic CHD which may be due to effect of chronic hypoxia and other conditions such as polycythemia.

\section{References:}

1.Cordina RL, Celermajer DS (2010): Chronic cyanosis and vascular function:implications for patients with cyanotic congenital heart disease. Cardiol Young,203:242-53.

2.Dimopoulos K, Diller GP, Koltsida $E$ et al. (2008): Prevalence, predictors, and prognostic value of renal dysfunction in adults with congenital heart disease. Circulation,117(18):2320-8.

3.Sahai A, Mei C, Schrier RW, Tannen R (2015): Mechanism of chronic hypoxia-induced renal cell growth. Kidney Int., 56:1277-81.

4.Tennant PW, Pearce MS, Bythell M, Rankin J(2010): 20-year survival of children born with congenital anomalies: a population-based study. Lancet, 375:649-56.

5.Wren C, Irving CA, Griffiths JA( 2012): Mortality in infants with cardiovascular malformations. Eur J Pediatr., 171:281.
6.Khoshnood B, Lelong N, Houyel L (2012): Prevalence, timing of diagnosis and mortality of newborns with congenital heart defects: a population-based study. Heart, 98:1667.

7.Billett J, Majeed A, Gatzoulis M (2008): Trends in hospital admissions, in-hospital case fatality and population mortality from congenital heart disease in England, 1994 to 2004. Heart, 94(3):342-8.

8.Formigari R, Michielson G, Digilio MC (2009): Genetic syndromes and congenital heart defects: how is surgical management affected? Eur J Cardio-Thorac Surg., 35:606-14.

9.Lin AE, Pober BR, Adiata I (2007): Congenital diaphragmatic hernia and associated cardiovascular malformations: type, frequency, and impact on management. Am J Med Genet C Semin Med Genet., 145C:201-16.

10.Jianyong $Z$, Yong $Y$, Ling $H$, Yanyan $X$ (2013): Renal function and injury in infants and young children with congenital heart disease. Pediatr Nephrol ., 28:99-104.

11.Patel KL, Mhetras SB, Varthakavi PK, Merchant PC, Nihalani KD (2011): Microalbuminuria in insulin dependent diabetes mellitus. J Assoc Physicians India, 47(6)589-95.

12.Agras PI, Derbent M, Ozcay F, Baskin E, Turkoglu S, Aldemir D et al. (2005) Effect of congenital heart disease on renal function in childhood. Nephron Physiol., 99: 10-5.

13.Majid M, Shamsi G, Mohammad RG, Mahmood S, Bahman $R$, Pooya $M$ (2011):Proteinuria in congenital heart disease: is it a real problem? J Cardiovasc Thorac Res., 3 (1): $17-21$.

14.Hesham A, Ibrahim E, Moustafa A, Salwa E (2003): Glomerular and tubular dysfunction in children with congenital cyanotic heart disease: effect of palliative surgery. Am J Med Sci.,1325(3): 110-4. 